\title{
The "Snacking Child" and its social network: some insights from an italian survey
}

\author{
Dario Gregori ${ }^{1 *}$, Francesca Foltran ${ }^{1}$, Marco Ghidina ${ }^{2}$, Federica Zobec ${ }^{2}$, Simonetta Ballali ${ }^{3}$, Laura Franchin ${ }^{2}$ and \\ Paola Berchialla ${ }^{4}$
}

\begin{abstract}
Background: The hypothesis underlying this work is that the social network of a child might have an impact on the alimentary behaviors, in particular for what concerns snack consumption patterns.

Methods: 1215 Italian children 6-10 ys old were interviewed using a CATI facility in January 2010. 608 "snackers" and 607 "no-snackers" were identified. Information regarding family composition, child and relatives BMI, mother perception of child weight, child, father and mother physical activity, TV watching, social network, leisure time habits and dietary habits of peers, were collected. Association of variables with the status of snacker was investigated using a multivariable logistic regression model.

Results: Snackers children seem to be part of more numerous social network (1.40 friends vs $1.14, p=0.042)$ where the majority of peers are also eating snacks, this percentage being significantly higher ( 89.5 vs $76.3, p<$ 0.001) than in the "no-snacker" group. The snacking group is identified by the fact that it tends to practice at least 4 hours per week of physical activity (OR: 1.36, Cl: 1.03-1.9). No evidence of an association between snacking consumption and overweight status has been shown by our study.

Conclusions: The snacking child has more active peer-to-peer social relationships, mostly related with sport activities. However, spending leisure time in sportive activities implies being part of a social environment which is definitely a positive one from the point of view of obesity control, and indeed, no increase of overweight/obesity is seen in relation to snack consumption.
\end{abstract}

Keywords: snacks, overweight in children, social networks, physical activity

\section{Background}

Child obesity has been described as the product of an interaction between a susceptible host and an environment promoting the disease, and results when energy intake exceeds energy expenditure [1,2]. Studies finalized to identify behaviors acting as obesity promoters have been mainly focused on evaluating the role of dietary habits in terms of energy intake source [3], and the role of physical activity as a way to increase the energy expenditure [4]. Moreover, recent studies have been addressed to understand individual, familiar and

\footnotetext{
* Correspondence: dario.gregori@unipd.it

${ }^{1}$ Laboratory of Epidemiological Methods and Biostatistics, Department of Environmental Medicine and Public Health, University of Padova, via Loredan 18, 35031 Padova, Italy

Full list of author information is available at the end of the article
}

environmental factors determining behaviors suspected to be unhealthy $[5,6]$.

Among alimentary behaviors, snacking activity has been identified as one potential cause of obesity and/or overweight in childhood and adolescent [7]. Following Hampl [8], a child who's getting more than $15-20 \%$ of his/her daily caloric intake from snacks can be defined as a "snacker". Snacks are suspected to be obesity promoters because they are high-fat and high-sugar foods. Nevertheless, even if the percentage of energy from dietary fat or from sugar has been widely investigated as determinant of body fat accumulation, the existence of causal relationships between single nutrients or foods and obesity is controversial. In fact, while cross-sectional studies seem to be suggestive of an association, prospective cohort studies have frequently failed in finding such a correlation. Moreover, snacking has been related with 
other behaviors, such as TV watching, which are all believed to be, by itself, obesogenic; in this way, a pattern of potentially unhealthy behaviors has been described, identifying snacking children as having a sedentary lifestyle and spending the majority of leisure time alone [9]. However, snacking is also related with social and group activities, as an accompanying activity during social meetings and after them [10]. Social pattern of interaction are of course very different when referred to adults than for children. Nevertheless, for both, the relevant support provided by social networks in maintaining health and well-being has been recently recognized, but the joint effect of snacking activity and social relationships on obesity has been not really investigated, although several reports suggest the existence of an inverse relation among these factors [11-13].

The hypothesis underlying this work is that the social network might have an impact on the alimentary behaviors of the child, and in particular, for what is concerning the snacking activity, that: (i) "snacking" is not an individual or family-restricted choice, but instead that the involvement of peers is relevant with respect to this behavior, thus implying that the probability of being a "snacker" is higher in a context were other peers are also "snackers", and that (ii) increased calories intake due to "snacking" might be even compensated by a child who is inserted in a social network, if the latter is active from the perspective of exercise and physical activity.

To this purposes, a survey on children in Italy has been conducted, identifying both a group of "snackers" and one of "no-snackers", and comparing them in terms of social networks and leisure time behaviors, as well as in terms of overweight prevalence.

\section{Materials and methods}

Study conduction and identification of the social network The survey has been conducted using a CATI (Computer Assisted Telephone Interview) facility on 1215 children age 6-10 years, in January 2010 in Italy. Calls have been conducted by experienced CATI operator. The sample has been stratified according to the definition of snacker, thus collecting information on 608 "snackers" and 607 "no-snackers" children.

One-thousand two-hundred fifteen mothers, randomly selected through an automated system afferent to the Italian landline phone directory have been asked to answer directly on their child and on the group of the closest friends of him/her, defined within a limit of 10 children per referenced child. The random sample was constructed in a way to approximately provide an equal geographical distribution of the families in the North, in the Center and in the South of Italy.

\section{Interviews}

The study is based on telephone interview on a randomly chosen set of mothers living in Italy and with a cable-phone connection. Informed consent was obtained from people interviewed before starting the set of questions.

First, mothers answering to the phone calls were asked to provide information useful for stratifying the child as "snacker" or "no-snacker". Thus, the questionnaire was divided into 4 parts. The first part investigated on basic sociodemographic characteristics, like education, composition of the family and work. In the second section mothers were asked to answer about family's physical characteristics, like weight and height. The third part assessed the behavioral aspects of their children, like weekly hours of physical activity and more details on the consumption patterns of snacks. The latter part regarded children's social network; mothers were asked to answer on their children's friends, up to a maximum of 10 children, on snacking habits, physical activities and perception of their nutritional status.

\section{Definitions}

The "snacker" has been defined as consuming at least 3 or more of the following products per day: filled cakes/ sweet snacks, plain cakes/sweet snacks, chocolate snacks, sodas (no sugar-free) in can or bottle. This adds up to an average of at least 360-400 calories, which counts up to $18-22 \%$ of the recommended daily caloric intake for a child (about 1700-1900 calories per day in the age class 6-10) and it is coherent with the definition of the "snacker" as provided in the literature [8].

Body mass index (BMI) was calculated as weight $(\mathrm{kg}) /$ height ${ }^{2}(\mathrm{~m})$. According to the present guidelines, in adults, normal weight, overweight and obesity were defined as a BMI $<25.0 \mathrm{~kg} / \mathrm{m}^{2}, 25.0-29.9 \mathrm{~kg} / \mathrm{m}^{2}$, and $\geq$ $30.0 \mathrm{~kg} / \mathrm{m}^{2}$, respectively [14]. Data on weight and height of the child, used to compute the BMI were updated in $76 \%$ of the cases to the last three months and they, in the remaining $24 \%$, never exceeded the year. Children were defined as obese according to the percentile to which they were belonging, according to their age, as indicated from the CDC (Centers for Disease Control and Prevention) pediatric growths charts [15]; thus, they were defined as "at risk for overweight" if their weight was between the $85^{\text {th }}$ and the $95^{\text {th }}$ percentile and as "overweight" is greater than the $95^{\text {th }}$ percentile [16] CDC pediatrics growth charts were chosen as recommended when assessing growth's parameters of children older than 2 years $[17,18]$.

\section{Statistical Methods}

Continuous variables are expressed as median and interquartile difference and categorical variables as 
percentages and absolute numbers. Differences between groups were compared using Wilcoxon and McNemar or Chi-Square tests $[19,20]$, as appropriate.

All variables investigated are listed in Tables 1 and 2 . Association of variables with the status of snacker has been investigated using a multivariable logistic regression model. Association of variables with the BMI level of the children in the "snacker" group has been investigated using a multivariable linear regression model. The following model building strategy applies to both models. Variables related (with a maximum p-value of the association, as resulting in the univariable analysis, of $0.25)$, to the network around the snacker have been also inserted in the model and final estimates have been adjusted for inter-network correlation using a HuberWhite estimating equation approach.

All variables considered were entered into the model "as is", i.e. without any transformation or cutting-off. If a significant non-linearity using a score test was found, in relating the covariate's effect with survival, the specific covariate's effect was modeled using a restricted cubic spline. Selection criteria was the AIC (Akaike Information Criterion) applied backward for selecting significant covariates. The final model for each of the three steps was selected if superior in terms of AIC at a significance level of 0.05 and $\mathrm{p}$-values have been explicitly indicated if below the 0.25 threshold, otherwise the "NS" indication is used.

To account for possible overfitting in the regression models secondary to high ratio between covariates and events, cross-validation and bootstrap (200 runs) techniques were applied. For the logistic regression model, Somer's concordance Index Dxy (the closer to one in absolute value the better) were obtained and evaluated for this purpose.

Multivariate Odds Ratios have been presented along with their 95\% confidence intervals for the logistic regression model, whereas for the linear regression model effects on BMI scale have been presented along with their 95\% confidence levels.

The statistical significance was settled at a p-value $<0.05$. The R System (release 2.7.0) statistical package and the Harrell's Design and Hmisc libraries were used for analysis.

\section{Results}

The interviews were balanced by design in terms of geographical distribution, with $326(26.8 \%)$ in the North, $422(34.7 \%)$ in the Center and $467(38.4 \%)$ in the South of Italy.

The sample is described in Table 1 for what concerns family characteristics and in Table 2 for what regards children.

\section{Snacks}

The snacking activity, according to the definition adopted in the study, was eating at least three snacks per day. The distribution of snacks were: Plain cakes 230 (39.2\%), Cream filled cakes 336 (57.2\%), Chocolate cakes 227 (38.7\%), Sugar sodas 299 (50.9\%) and other types $16(2.7 \%)$.

\section{The social network}

The network around the reference child is described in Table 3. The social network identified according the strict rules adopted in the study was composed by on average 1.27 friends per child surveyed, slightly but significantly higher for "snackers" than for "no-snackers" (1.40 vs $1.14, \mathrm{p}=0.042$ ).

\section{Multivariable analysis for characterizing the "snacker"}

To understand which individual, familiar or social network characteristics are associated with the status of "snacker", a multivariable model has been built, following the variable selection procedure as described in the statistical section among all variables listed in Table 1 and in Table 2. Results of the multivariable model are presented in Table 4.

\section{Multivariable analysis for the BMI levels in the "snacker" group}

To understand which individual, familiar or social network characteristics are associated with any given BMI of the "snacker", a multivariable model has been built, following the variable selection procedure as described in the statistical section among all variables listed in Table 1 and in Table 2 but limited to the group of the 608 "snackers". Results from this multivariable analysis are shown in Table 5.

\section{Discussion}

\section{Familiar and social environment role in determining snacking activity}

Results of the limited research on behavioral mediators of familial patterns of overweight indicate that parents' own eating behaviors and parenting practices influence the development of children's eating behaviors, mediating familial patterns of overweight. Parents provide food environments for their children's early experiences with food and eating, and overweight parents seem to select environments that promote overweight among their children [21].

In our study two parental characteristics have been evaluated in relation to child eating behavior: parental BMI and parental habit to practice physical activity.

No association between fathers' BMI and child snacking consumption has been found, while the association 


\begin{tabular}{|c|c|c|c|c|c|c|c|}
\hline & $N$ & Snacker & $\begin{array}{c}\text { No } \\
\text { snacker }\end{array}$ & Overall & $p$-value ${ }^{7}$ & $B M I$ & $p$-value ${ }^{2}$ \\
\hline & & 608 & 607 & 1215 & & $\begin{array}{r}\text { (Snackers } \\
\text { only) }\end{array}$ & \\
\hline Number of children in the family & & & & & $p<0.001$ & & $p=0.232$ \\
\hline One & & $63(10.4)$ & $109(18.0)$ & $172(14.2)$ & & $17.6[15.2 ; 19.2]$ & \\
\hline Two or more & & $545(89.6)$ & $498(82.0)$ & $\begin{array}{r}1043 \\
(85.8)\end{array}$ & & $17.3[15.3 ; 20.4]$ & \\
\hline Number of Children in the family aged $6-10 \mathrm{yrs}$ & & & & & $p=0.001$ & & $p=0.047$ \\
\hline One & & $395(65.0)$ & $450(74.1)$ & $845(69.5)$ & & $17.8[15.3 ; 20.4]$ & \\
\hline Two or more & & $213(35.0)$ & $157(25.9)$ & $370(30.5)$ & & $16.6[15.3 ; 19.0]$ & \\
\hline Family Composition & & & & & $p=0.003$ & & $p=0.017$ \\
\hline Normal (father, mother and children) & & $527(86.7)$ & $558(91.9)$ & $\begin{array}{r}1085 \\
(89.3)\end{array}$ & & $17.6[15.3 ; 19.2]$ & \\
\hline $\begin{array}{l}\text { Enlarged (normal with grandparents or other relatives living } \\
\text { together) }\end{array}$ & & $81(13.3)$ & $49(8.1)$ & $130(10.7)$ & & $16.6[16.0 ; 23.1]$ & \\
\hline Father's Education & 1213 & & & & $p<0.001$ & & $p=0.005$ \\
\hline Up to the mandatory school & & $312(51.3)$ & $233(38.5)$ & $545(44.9)$ & & $17.6[15.9 ; 20.4]$ & \\
\hline High school degree & & $225(37.0)$ & $270(44.6)$ & $495(40.8)$ & & $17.8[15.2 ; 19.2]$ & \\
\hline BS or more & & $71(11.7)$ & $102(16.9)$ & $173(14.3)$ & & $15.9[13.9 ; 20.0]$ & \\
\hline Mother's Education & 1208 & & & & $p=0.001$ & & $p=0.060$ \\
\hline Up to the mandatory school & & $246(40.8)$ & $208(34.4)$ & $454(37.6)$ & & $17.8[16.0 ; 20.7]$ & \\
\hline High school degree & & $306(50.7)$ & $309(51.1)$ & $615(50.9)$ & & $17.3[15.2 ; 19.0]$ & \\
\hline BS or more & & $51(8.5)$ & $88(14.5)$ & $139(11.5)$ & & $17.5[14.5 ; 19.4]$ & \\
\hline Father's Job & 1211 & & & & $p=n s$ & & $p=0.005$ \\
\hline Independent worker & & $221(36.3)$ & $237(39.3)$ & $458(37.8)$ & & $18.1[15.3 ; 20.4]$ & \\
\hline Dependent worker & & $377(62.0)$ & $359(59.5)$ & $736(60.8)$ & & $17.1[15.3 ; 19.2]$ & \\
\hline Other (retired, unemployed) & & $10(1.6)$ & $7(1.2)$ & $17(1.4)$ & & $15.3[15.3 ; 15.3]$ & \\
\hline Mother's Job & 1207 & & & & $p=n s$ & & $p=0.010$ \\
\hline Independent worker & & $91(15.1)$ & $89(14.7)$ & $180(14.9)$ & & $16.6[15.9 ; 18.2]$ & \\
\hline Dependent worker & & $247(41.0)$ & $257(42.5)$ & $504(41.8)$ & & $17.3[14.9 ; 19.0]$ & \\
\hline Other (retired, unemployed, housewife) & & $265(43.9)$ & $258(42.7)$ & $523(43.3)$ & & $17.8[15.9 ; 20.8]$ & \\
\hline Mother has a full time job ( $40 \mathrm{hrs}$ per week) & 1207 & & & & $\mathrm{p}=\mathrm{ns}$ & & $p=0.053$ \\
\hline Yes & & $129(38.7)$ & $134(39.0)$ & $263(38.8)$ & & $16.5[14.9 ; 19.0]$ & \\
\hline No & & $204(61.3)$ & $210(61.0)$ & $414(61.2)$ & & $17.8[15.3 ; 18.3]$ & \\
\hline Who is taking care of the child outside schooltime & 1213 & & & & $p=0.009$ & & $p<0.001$ \\
\hline Mother/Father & & $499(82.1)$ & $529(87.4)$ & $\begin{array}{r}1028 \\
(84.7)\end{array}$ & & $17.6[15.9 ; 20.4]$ & \\
\hline Other people & & 109 (17.9) & $76(12.6)$ & $185(15.3)$ & & $15.3[14.6 ; 18.8]$ & \\
\hline Exercise Time (hours per week) of the mother & 1175 & & & & $p<0.001$ & & $p<0.001$ \\
\hline None & & $428(74.8)$ & $416(69.0)$ & $844(71.8)$ & & $16.7[15.3 ; 18.8]$ & \\
\hline Between one and three hours & & $68(11.9)$ & $138(22.9)$ & $206(17.5)$ & & $19.0[17.8 ; 20.8]$ & \\
\hline Four hours or more & & $76(13.3)$ & $49(8.1)$ & $125(10.6)$ & & $18.3[14.9 ; 20.4]$ & \\
\hline Mother's BMI & 1161 & $\begin{array}{r}23[21 ; \\
24]\end{array}$ & $22[20 ; 24]$ & $22[20 ;$ & $p=0.015$ & & $p<0.001$ \\
\hline Underweight/normal & & $454(79.9)$ & $472(79.6)$ & $926(79.8)$ & $p=0.002$ & $16.7[15.3 ; 18.8]$ & \\
\hline Overweight & & $72(12.7)$ & $101(17.0)$ & $173(14.9)$ & & $20.0[17.6 ; 20.4]$ & \\
\hline Obese & & $42(7.4)$ & $20(3.4)$ & $62(5.3)$ & & $21.4[14.3 ; 23.4]$ & \\
\hline Exercise Time (hours per week) of the father & 1176 & & & & $p=n s$ & & $p=0.025$ \\
\hline None & & $425(73.7)$ & $424(70.8)$ & $849(72.2)$ & & $17.4[15.8 ; 19.2]$ & \\
\hline Between one and three hours & & $93(16.1)$ & $100(16.7)$ & $193(16.4)$ & & $17.8[15.3 ; 20.8]$ & \\
\hline Between four and six hours & & $43(7.5)$ & $57(9.5)$ & $100(8.5)$ & & $18.3[14.9 ; 19.2]$ & \\
\hline Seven hours or more & & $16(2.8)$ & $18(3.0)$ & $34(2.9)$ & & $14.8[11.6 ; 22.4]$ & \\
\hline
\end{tabular}


Table 1 Description of the families surveyed. (Continued)

\begin{tabular}{|c|c|c|c|c|c|c|c|}
\hline Father's BMI & 1100 & $\begin{array}{r}25[24 ; \\
27]\end{array}$ & $25[24 ; 27]$ & $\begin{array}{r}25[24 ; \\
27]\end{array}$ & $p=0.152$ & & $p<0.001$ \\
\hline Underweight/normal & & $265(48.4)$ & $285(51.5)$ & $550(50.0)$ & $\mathrm{p}=\mathrm{ns}$ & $16.6[15.3 ; 18.7]$ & \\
\hline Overweight & & $243(44.4)$ & $227(41.0)$ & $470(42.7)$ & & $17.8[15.1 ; 20.7]$ & \\
\hline Obese & & $39(7.1)$ & $41(7.4)$ & $80(7.3)$ & & $18.3[17.6 ; 22.8]$ & \\
\hline Nationality of the family & 1193 & & & & $p=n s$ & & $p=0.003$ \\
\hline Italian & & $557(94.7)$ & $579(95.7)$ & $\begin{array}{r}1136 \\
(95.2)\end{array}$ & & $17.4[15.3 ; 19.8]$ & \\
\hline Mixed Italian and other nationality & & $21(3.6)$ & $20(3.3)$ & $41(3.4)$ & & $21.4[15.3 ; 25.7]$ & \\
\hline Other nationality & & $10(1.7)$ & $6(1.0)$ & $16(1.3)$ & & - & \\
\hline
\end{tabular}

$\mathrm{N}$ refers to the number of valid responses. If no indicated, the number is 1215 . Absolute numbers and percentages. $\mathrm{P}$-value ${ }^{1}$ refers to the significance of the difference among snackers and no snackers, $\mathrm{p}$-value ${ }^{2}$ to the difference in $\mathrm{BMI}$ across categories of each variable in the snackers only group.

between mothers' BMI and child snacking consumption observed in the univariate analysis disappears in multivariable analysis.

On the other hand, in our study children dietary habits seems to be strictly related to mothers' attitude toward physical activity. Indeed, mothers of no-snackers seem to be more prone to healthy behaviors, practicing at least 2 hours of sport activities during the week. But this not necessarily translates in a healthier lifestyle for their children, since no-snackers children tend have a more sedentary lifestyle.

On the contrary, snacking children profile is controversial, since, in according to the literature, they spend more time than no-snackers watching TV, but also, they seem to be more active, since the great part of them practices at least 4 hours per week of physical activity. Differences in family composition could explain this fact: while no-snacking children usually may come from classical families (father, mother and children) and may have not brothers or sisters, snacking children frequently come from numerous, enlarged families. Classical families having one child, may pay more attention on their children lifestyle and on their dietary habits, whereas, in an enlarged familiar environment, parents may have to delegate other people or relatives, such as grandparents, to take care of their children, ending up in a less strict control of their children's dietary habits.

Differently from what described in previous studies on snacking activities [22], in which snacking children are largely described as children usually spending time in solitary activities, in our analysis snacking children, having a more active lifestyle than no-snackers, are part of a more numerous social networks. Thus, instead of observing the well-studied vicious circle in which more isolated children stay at home, spending time in sedentary activity and eating snacks [22], we observed that snacking children are practicing physical activity more than no-snackers and are part of a larger social network. Indeed, in the snackers' social network, most of peers are both practicing sports and eating snacks. The attitude to "regress to the mean" in term of behaviors among peers, with the tendency of mimicking others' behaviors [23] could also contribute to explain these findings.

On the contrary, as a direct consequence of a more sedentary lifestyle, no-snackers children have less social relationships and, similarly to that observed among snackers, their peers tend to share the same eating and leisure time habits.

\section{Snacking and overweight}

The existence of an association between snack consumption and risk of being overweight or obese has been previously evaluated in numerous studies obtaining contrasting results: is was shown in some studies but not in others [9].

In our study we found that the status of snacker seems not to be associated with overweight and/or obesity being the BMI equivalent among snacking and not snacking children. The key factor in explaining such result might be the role of physical activity of the child. In addition to the positive effect of physical activity, by itself, on obesity prevention, also spending leisure time in sportive activities implies being part of a social environment which is definitely a positive one from the point of view of obesity control [24]. Indeed, results do not show an increase of overweight/obesity in relation to snack consumption.

\section{Factors related to $\mathrm{BMI}$ in the snacking group}

In the present study, determinants of BMI in snacking group have been explored; according to previous largescale researches which found correlations between paternal or maternal anthropometric measures and children's adiposity [25-27], also in our analysis an increment in mother BMI seems to contribute to an increment in children BMI. As previously mentioned, this intergenerational relationship reflects genetic, social, cultural, and environmental components since, when parents make food consumption choices (or provide the 
Table 2 Description of the children surveyed.

\begin{tabular}{|c|c|c|c|c|c|c|c|}
\hline & $N$ & $\begin{array}{c}\text { Snacker } \\
608\end{array}$ & $\begin{array}{c}\text { No snacker } \\
607\end{array}$ & $\begin{array}{c}\text { Overall } \\
1215\end{array}$ & $p$-value ${ }^{7}$ & $\begin{array}{c}B M I \\
\text { (Snackers only) }\end{array}$ & $p$-value ${ }^{2}$ \\
\hline Gender & & & & & $p=n s$ & & $p=0.214$ \\
\hline Male & & $344(56.6)$ & $331(54.5)$ & $675(55.6)$ & & $17.8[15.9 ; 20.0]$ & \\
\hline Female & & $264(43.4)$ & $276(45.5)$ & $540(44.4)$ & & $17.1[14.9 ; 20.4]$ & \\
\hline Age (years) & & & & & $p<0.001$ & & $p<0.001$ \\
\hline 6 & & $128(21.1)$ & $121(19.9)$ & $249(20.5)$ & & $16.5[14.9 ; 19.0]$ & \\
\hline 7 & & $120(19.7)$ & $102(16.8)$ & $222(18.3)$ & & $18.0[16.0 ; 20.0]$ & \\
\hline 8 & & $167(27.5)$ & $114(18.8)$ & $281(23.1)$ & & $15.9[14.6 ; 20.7]$ & \\
\hline 9 & & $102(16.8)$ & $135(22.2)$ & $237(19.5)$ & & $17.1[16.2 ; 20.4]$ & \\
\hline 10 & & $91(15.0)$ & $135(22.2)$ & $226(18.6)$ & & $17.8[17.4 ; 19.8]$ & \\
\hline BMI & 1082 & $17[15 ; 20]$ & $18[15 ; 20]$ & $18[15 ; 20]$ & $p=0.120$ & & $p<0.001$ \\
\hline Underweight/normal & & $326(60.3)$ & $325(60.1)$ & $651(60.2)$ & & $15.9[14.6 ; 16.8]$ & \\
\hline At risk of overweight & & $91(16.8)$ & $101(18.7)$ & $192(17.7)$ & & $18.3[18.1 ; 20.4]$ & \\
\hline Overweight & & $124(22.9)$ & $115(21.3)$ & $239(22.1)$ & & $21.9[20.7 ; 23.4]$ & \\
\hline Interest of the child for the snack & 1145 & & & & $p=n s$ & & $p<0.001$ \\
\hline Focused on the product & & $208(35.9)$ & $173(30.6)$ & $381(33.3)$ & & $18.3[16.5 ; 20.4]$ & \\
\hline Focused on the gadget accompanying the snack & & $372(64.1)$ & $392(69.4)$ & $764(66.7)$ & & $16.6[14.9 ; 19.0]$ & \\
\hline Age of the mother at time of child birth & 1187 & $30[27 ; 33]$ & $31[28 ; 34]$ & $30[28 ; 33]$ & $p<0.001$ & $17.4[15.3 ; 20.0]$ & \\
\hline Time of sleeping of the child per day & 1187 & & & & $p=0.002$ & & $p<0.001$ \\
\hline At most 8 hours & & $210(36.0)$ & $168(27.8)$ & $378(31.8)$ & & $18.0[16.0 ; 20.7]$ & \\
\hline More than 8 hours & & $373(64.0)$ & $436(72.2)$ & $809(68.2)$ & & $16.7[15.2 ; 19.4]$ & \\
\hline Time when the child wakes up & 1186 & & & & $\mathrm{p}=\mathrm{ns}$ & & $p<0.001$ \\
\hline 7.30 AM or earlier & & $369(63.3)$ & $402(66.7)$ & $771(65.0)$ & & $17.1[14.9 ; 19.2]$ & \\
\hline Between $7.30 \mathrm{AM}$ and $8.30 \mathrm{AM}$ & & $101(17.3)$ & $105(17.4)$ & $206(17.4)$ & & $18.1[16.7 ; 21.0]$ & \\
\hline After $8.30 \mathrm{AM}$ & & $113(19.4)$ & $96(15.9)$ & $209(17.6)$ & & $17.1[16.0 ; 20.6]$ & \\
\hline Number of meals per day of the child & 1188 & & & & $p<0.001$ & & $p<0.001$ \\
\hline At most three & & $69(11.8)$ & $132(21.8)$ & $201(16.9)$ & & $16.9[14.5 ; 17.9]$ & \\
\hline Four & & $334(57.3)$ & $334(55.2)$ & $668(56.2)$ & & $16.8[15.3 ; 20.0]$ & \\
\hline Five or more & & $180(30.9)$ & $139(23.0)$ & $319(26.9)$ & & $18.3[16.0 ; 20.4]$ & \\
\hline Place of meals & 1209 & & & & $p=0.088$ & & $p=0.010$ \\
\hline At home & & $538(89.2)$ & $558(92.1)$ & $1096(90.7)$ & & $17.6[15.3 ; 20.0]$ & \\
\hline Outside home & & $65(10.8)$ & $48(7.9)$ & $113(9.3)$ & & $16.5[14.9 ; 17.8]$ & \\
\hline The place of meals is changing during the week & 1208 & & & & $\mathrm{p}=\mathrm{ns}$ & & $p=0.065$ \\
\hline Yes & & $217(36.0)$ & $205(33.9)$ & $422(34.9)$ & & $17.3[14.9 ; 20.0]$ & \\
\hline No & & $386(64.0)$ & $400(66.1)$ & $786(65.1)$ & & $17.6[15.4 ; 20.4]$ & \\
\hline Number of different sport activities per week & 1190 & & & & $\mathrm{p}=\mathrm{ns}$ & & $p=0.008$ \\
\hline None & & $175(29.5)$ & $176(29.5)$ & $351(29.5)$ & & $17.6[16.0 ; 20.4]$ & \\
\hline One sport & & $312(52.6)$ & $318(53.3)$ & $630(52.9)$ & & $17.6[15.2 ; 20.0]$ & \\
\hline Two & & $82(13.8)$ & $85(14.2)$ & $167(14.0)$ & & $17.1[14.9 ; 20.4]$ & \\
\hline Three or more & & $24(4.0)$ & $18(3.0)$ & $42(3.5)$ & & $16.0[14.3 ; 17.5]$ & \\
\hline Time (hours) of sport activities per week & 1190 & & & & $\mathrm{p}=\mathrm{ns}$ & & $p=0.133$ \\
\hline None & & $175(29.5)$ & $176(29.5)$ & $351(29.5)$ & & $17.6[16.0 ; 20.4]$ & \\
\hline Between one and three hours & & $252(42.5)$ & $246(41.2)$ & $498(41.8)$ & & $17.8[14.8 ; 20.4]$ & \\
\hline More than three hours & & $166(28.0)$ & $175(29.3)$ & $341(28.7)$ & & $17.4[15.3 ; 19.2]$ & \\
\hline Hours per day watching TV or playing videogames & 1115 & & & & $p<0.001$ & & $p<0.001$ \\
\hline At most one hour & & $144(26.4)$ & $233(40.9)$ & $377(33.8)$ & & $17.4[14.5 ; 18.0]$ & \\
\hline Between one and two hours & & $224(41.1)$ & $215(37.7)$ & $439(39.4)$ & & $17.1[15.3 ; 20.2]$ & \\
\hline More than two hours & & $177(32.5)$ & $122(21.4)$ & $299(26.8)$ & & $17.8[15.9 ; 20.4]$ & \\
\hline Hours of studying outside school time & 1041 & & & & $p=0.113$ & & $p=0.006$ \\
\hline At most three hours & & $116(23.2)$ & $131(24.2)$ & $247(23.7)$ & & $16.8[14.5 ; 20.7]$ & \\
\hline Between three and seven hours & & $179(35.8)$ & $221(40.9)$ & $400(38.4)$ & & $17.4[15.3 ; 19.0]$ & \\
\hline
\end{tabular}


Table 2 Description of the children surveyed. (Continued)

\begin{tabular}{|c|c|c|c|c|c|c|c|}
\hline More than seven hours & & $205(41.0)$ & $189(34.9)$ & $394(37.8)$ & & $18.1[16.0 ; 20.4]$ & \\
\hline What is your perception on the weight of your child & 1204 & & & & $p=n s$ & & $p<0.001$ \\
\hline He/she is underweight & & $69(13.9)$ & $60(11.7)$ & $129(12.8)$ & & $14.5[13.8 ; 15.3]$ & \\
\hline $\mathrm{He} /$ she is normal & & $428(86.1)$ & $454(88.3)$ & $882(87.2)$ & & $16.8[15.3 ; 19.0]$ & \\
\hline $\mathrm{He} /$ she is overweight & & $101(16.9)$ & $92(15.2)$ & $193(16.0)$ & & $20.6[18.1 ; 22.8]$ & \\
\hline How much, in $\mathrm{Kg}$ & 298 & $4[3 ; 5]$ & $3[2 ; 5]$ & $3[2 ; 5]$ & $p<0.001$ & $18.1[14.6 ; 21.4]$ & \\
\hline How much (in case of overweight), in $\mathrm{Kg}$ & 182 & $5[3 ; 10]$ & $3[2 ; 6]$ & $4[2 ; 7]$ & $p<0.001$ & $20.6[18.1 ; 22.8]$ & \\
\hline Number of close friends aged 6-10 yrs & 1135 & & & & $p=0.188$ & & $p=0.001$ \\
\hline None & & $39(6.9)$ & $56(9.8)$ & $95(8.4)$ & & $18.9[14.3 ; 22.8]$ & \\
\hline Between one and three & & $100(17.7)$ & $93(16.3)$ & $193(17.0)$ & & $17.8[16.7 ; 20.8]$ & \\
\hline More than three & & $427(75.4)$ & $420(73.8)$ & $847(74.6)$ & & $17.6[15.3 ; 19.2]$ & \\
\hline
\end{tabular}

$\mathrm{N}$ refers to the number of valid responses. If no indicated, the number is 1215 . Absolute numbers and percentages. P-value ${ }^{1}$ refers to the significance of the difference among snackers and no snackers, $\mathrm{p}$-value ${ }^{2}$ to the difference in BMI across categories of each variable in the snackers only group.

Table 3 Description of the social network of the index child.

\begin{tabular}{|c|c|c|c|c|c|c|c|}
\hline & $N$ & $\begin{array}{c}\text { Snacker } \\
858\end{array}$ & $\begin{array}{c}\text { No snacker } \\
658\end{array}$ & $\begin{array}{c}\text { Overall } \\
1516\end{array}$ & $p$-value ${ }^{1}$ & $\begin{array}{c}B M I \\
\text { (Snackers only) }\end{array}$ & $p$-value ${ }^{2}$ \\
\hline Gender & 1510 & & & & $\mathrm{p}=\mathrm{ns}$ & & $p=0.093$ \\
\hline Male & & $468(54.9)$ & $367(55.8)$ & $835(55.3)$ & & $17.4[15.9 ; 19.0]$ & \\
\hline Female & & $384(45.1)$ & $291(44.2)$ & $675(44.7)$ & & $17.6[16.0 ; 20.4]$ & \\
\hline Age & 1510 & & & & $p=0.005$ & & $p<0.001$ \\
\hline At most 8 yrs & & $498(58.5)$ & $337(51.2)$ & $835(55.3)$ & & $16.6[15.3 ; 19.2]$ & \\
\hline Older than 8 yrs & & $354(41.5)$ & $321(48.8)$ & $675(44.7)$ & & $17.8[16.6 ; 20.4]$ & \\
\hline Place of friendship & 1496 & & & & $\mathrm{p}=\mathrm{ns}$ & & $p=0.003$ \\
\hline School & & $570(67.9)$ & $467(71.2)$ & $1037(69.3)$ & & $17.7[15.3 ; 20.4]$ & \\
\hline Child of a relative & & $126(15.0)$ & $97(14.8)$ & $223(14.9)$ & & $16.8[15.8 ; 20.4]$ & \\
\hline Neighbor & & $114(13.6)$ & $75(11.4)$ & $189(12.6)$ & & $17.7[16.5 ; 20.7]$ & \\
\hline Sport/other places & & $30(3.6)$ & $17(2.6)$ & $47(3.1)$ & & $16.9[15.9 ; 17.8]$ & \\
\hline Time (hours) of sport activities per week & 1493 & & & & $p=0.002$ & & $p<0.001$ \\
\hline None & & $336(40.0)$ & $223(34.2)$ & $559(37.4)$ & & $17.6[16.5 ; 20.4]$ & \\
\hline Between one and three hours & & $306(36.4)$ & $296(45.3)$ & $602(40.3)$ & & $16.5[15.0 ; 20.0]$ & \\
\hline More than three hours & & $198(23.6)$ & $134(20.5)$ & $332(22.2)$ & & $17.8[16.0 ; 20.4]$ & \\
\hline Number of different sport activities per week & 934 & & & & $\mathrm{p}=\mathrm{ns}$ & & $p=0.018$ \\
\hline One sport activity & & $422(83.7)$ & $362(84.2)$ & $784(83.9)$ & & $17.1[15.3 ; 19.7]$ & \\
\hline Two or more sport activities & & $82(16.3)$ & $68(15.8)$ & $150(16.1)$ & & $17.8[15.9 ; 20.8]$ & \\
\hline Is the friend eating snacks & 1181 & & & & $p<0.001$ & & $p=0.200$ \\
\hline Yes & & $612(89.5)$ & $379(76.3)$ & $991(83.9)$ & & $17.8[16.0 ; 20.4]$ & \\
\hline No & & $72(10.5)$ & $118(23.7)$ & $190(16.1)$ & & $17.8[16.6 ; 21.0]$ & \\
\hline Number of snacks per day of the friend & 668 & & & & $\mathrm{p}=\mathrm{ns}$ & & $p<0.001$ \\
\hline At most one & & $150(37.9)$ & 105 (38.6) & $255(38.2)$ & & $17.1[15.8 ; 18.1]$ & \\
\hline Not more than two & & $120(30.3)$ & $88(32.4)$ & $208(31.1)$ & & $18.3[16.5 ; 20.4]$ & \\
\hline Not more than three & & $96(24.2)$ & $53(19.5)$ & $149(22.3)$ & & $20.4[17.4 ; 22.4]$ & \\
\hline More than three & & $30(7.6)$ & $26(9.6)$ & $56(8.4)$ & & $16.5[15.3 ; 19.8]$ & \\
\hline What is your perception on the weight of your child & 1484 & & & & $p=0.82$ & & $p<0.001$ \\
\hline $\mathrm{He} /$ she is underweight & & $84(10.1)$ & $89(13.7)$ & $173(11.7)$ & & $19.0[16.7 ; 20.7]$ & \\
\hline $\mathrm{He} / \mathrm{she}$ is normal & & $588(70.5)$ & $432(66.5)$ & $1020(68.7)$ & & $17.4[15.4 ; 19.2]$ & \\
\hline $\mathrm{He} /$ she is overweight & & $162(19.4)$ & $129(19.8)$ & 291 (19.6) & & $17.8[16.5 ; 20.4]$ & \\
\hline
\end{tabular}

$\mathrm{N}$ refers to the number of valid responses. If no indicated, the number is 1516 . Absolute numbers and percentages. $\mathrm{P}$-value ${ }^{1}$ refers to the significance of the difference among snackers and no snackers, $\mathrm{p}$-value ${ }^{2}$ to the difference in BMI across categories of each variable in the snackers only group. 
Table 4 Multivariable logistic model for the association with the status of Snacker of selected variables.

\begin{tabular}{|c|c|c|c|c|}
\hline & Effect & $O R$ & $\mathrm{Cl}$ & $95 \%$ \\
\hline Age of the mother & 33 vs. 28 & 0.79 & 0.67 & 0.93 \\
\hline Time (hours) of sport activities per week of the mother & 2 vs. 0 & 0.55 & 0.38 & 0.79 \\
\hline Time (hours) of sport activities per week of the child & 4 vs. 2 & 1.36 & 1.03 & 1.9 \\
\hline Number of meals/day of the child & 5 vs. 2 & 3.22 & 1.49 & 6.98 \\
\hline Number of friends in the network & More than 3 vs. At most 3 & 1.28 & 1.01 & 1.71 \\
\hline Time (hours) of sport activities per week of the friends in the network & 4 vs. 2 & 1.18 & 1.05 & 1.43 \\
\hline Is the friend eating snacks? & Yes vs. No & 2.44 & 1.67 & 3.57 \\
\hline
\end{tabular}

Hours of sport activities of the mother and of the child are showing a non-linear effect (respectively, $p=0.002$ and $p=0.0009$ ). Somer's Dxy equal to 0.65.

feasible food consumption set) for children for meals eaten at home, this common environment generates a correlation between generations when both eat unhealthy (or healthy) food together [28].

Moreover, a positive relationship between maternal age and children BMI has also been found, suggesting that younger mothers tend to pay more attention to their children's dietary habits or to encourage them to practice sport.

As expected, energy balance-related behaviors, including sport activity, studying and watching TV are related to children BMI: an increment in the first one induces a $\mathrm{BMI}$ reduction, while, more time spent in sedentary activity determines a BMI increasing, as expected.

Finally, as observed elsewhere [29], a positive relationship between low income (indirectly measured here by the municipality income) and body weight seems to exist: the association of child and household food insecurity with childhood overweight has been demonstrated in several studies [30]; moreover, children in lowincome families could experience adverse psychosocial conditions which may contribute to poor eating habits and lower physical activity levels [31].

\section{Study limitations}

This study is a survey, without direct interaction between the investigator and the interviewed people and thus relying only on self-reported measurements for what concerns anthropometric characteristics, physical activity levels and dietary patterns. Although this approach has been widely used [32], it still presents the general limitation of such approaches, like reporting bias, barrier effect leading to interview refusal, tendency of ameliorant responses in presence of sensitive questions [31]. The authors used interview and analysis techniques to reduce each of such potential biases, like the involvement of only highly experienced interviewers in interview conduction and multivariable modeling for confounding adjustment.

\section{Final remarks}

No evidence of an association between snacking consumption and overweight status has been shown by our study. This fact can be explained by the different attitude toward physical activity observed in snackers and no-snackers: in fact, differently from common findings in scientific literature, in our study the snacking child can be described as practicing sport more than no-snakers and, as a consequence, having more active peer-topeer social relationships, mostly related with sport activities. Among snackers, factors traditionally related to body weight such as mother BMI, energy balancerelated behaviors and municipality income have been confirmed as major determinants of children BMI.

\section{Conclusions}

Obesity control appeared to be positively influenced by peer-to-peer social relationships, especially those related to sport activities. Snacking behavior didn't present association with overweight and obesity, that instead

Table 5 Multivariable model for the BMI of the "snacker" child.

\begin{tabular}{|c|c|c|c|c|c|}
\hline Variable & Value & Effect & S.E. & $\mathrm{Cl}$ & $95 \%$ \\
\hline Mother's BMI & 4 points increment & 0.85 & 0.12 & 0.62 & 1.08 \\
\hline Age (Mother) & 5 years increment & 0.73 & 0.17 & 0.41 & 1.06 \\
\hline Time studying per day (hours) & 6 hrs increment & 0.83 & 0.15 & 0.53 & 1.13 \\
\hline Time in sport activities per day (hours) & 3 hrs increment & -0.43 & 0.18 & -0.77 & -0.08 \\
\hline \multirow[t]{2}{*}{ Time in front of TV per day } & $\leq 1 \mathrm{~h}$ vs. $1-2 \mathrm{hrs}$ & -2.09 & 0.36 & -2.8 & -1.38 \\
\hline & $>2$ hrs vs. $1-2$ hrs & -0.26 & 0.29 & -0.83 & 0.3 \\
\hline Municipality income (low vs. high) & & 1.82 & 0.28 & 1.26 & 2.37 \\
\hline
\end{tabular}

Linear model for snackers only. The column "value" refers to the interquartile difference for continuous variables or for specific reference categories for categorical variables. 
were linked with families' characteristics, like income or parents' age and BMI. These conclusions point out the chiefly role of energy expenditure in regulating the energy gap, stressing the necessity of to consider obesity as a multifactorial disease, influenced by social behaviors, in first instance related with the familiar environment.

\section{List of abbreviations}

AIC: Akaike Information Criterion; BMI: Body Mass Index; CATI: Computer Assisted Telephone Interview; CDC: Centers for Disease Control and Prevention; Cl: Interval of Confidence; NS: Non Significant; OR: Odds Ratio

\section{Acknowledgements}

The authors would like to thank Zeta Research's CATI team for its role in data collection.

This research was partially funded by an unrestricted grant of the University of Padova and of Prochild ONLUS. The research did benefit also from a technical grant of ZETA Research Ltd for conducting the Survey.

\section{Author details}

${ }^{1}$ Laboratory of Epidemiological Methods and Biostatistics, Department of Environmental Medicine and Public Health, University of Padova, via Loredan 18, 35031 Padova, Italy. 'ZETA Research Inc., via Caccia 8, 34129 Trieste, Italy. ${ }^{3}$ Prochild ONLUS, Piazza San Giovanni 2, 34122 Trieste, Italy. ${ }^{4}$ Department of Public Health and Microbiology, University of Torino, via Santena 5 bis, 10126 Torino, Italy.

\section{Authors' contributions}

DG conceived the study, participated in its design and performed the statistical analysis; FF participated in the design of the study and coordinated and helped to draft the manuscript. MG coordinated data collection and participated in statistical analysis. FZ implemented and supervised survey conduction. SB participated in manuscript drafting. LF participated in manuscript drafting. PB performed the statistical analysis. All authors read and approved the final manuscript.

\section{Competing interests}

The authors declare that they have no competing interests.

Received: 22 August 2011 Accepted: 29 November 2011 Published: 29 November 2011

\section{References}

1. James PT, Leach R, Kalamara E, Shayeghi M: The worldwide obesity epidemic. Obes Res 2001, 9(Suppl 4):228S-233S.

2. Bray GA, Bellanger T: Epidemiology, trends, and morbidities of obesity and the metabolic syndrome. Endocrine 2006, 29(1):109-117.

3. Campbell KJ, Crawford DA, Ball K: Family food environment and dietary behaviors likely to promote fatness in 5-6 year-old children. Int $J$ Obes (Lond) 2006, 30(8):1272-1280.

4. Janssen I, Katzmarzyk PT, Boyce WF, Vereecken C, Mulvihill C, Roberts C, Currie C, Pickett W: Comparison of overweight and obesity prevalence in school-aged youth from 34 countries and their relationships with physical activity and dietary patterns. Obes Rev 2005, 6(2):123-132.

5. van der Horst K, Oenema A, Ferreira I, Wendel-Vos W, Giskes K, van Lenthe F, Brug J: A systematic review of environmental correlates of obesity-related dietary behaviors in youth. Health Educ Res 2007, 22(2):203-226.

6. Campbell K, Crawford DA, Salmon J, Carver A, Garnett SP, Baur LA: Associations between the home food environment and obesitypromoting eating behaviors in adolescence. Obesity (Silver Spring) 2007, 15(3):719-730.

7. Erlanson-Albertsson C, Zetterstrom R: The global obesity epidemic: snacking and obesity may start with free meals during infant feeding. Acta Paediatr 2005, 94(11):1523-1531.
8. Hampl JS, Heaton $\mathrm{CL}$, Taylor CA: Snacking patterns influence energy and nutrient intakes but not body mass index. J Hum Nutr Diet 2003, 16(1):3-11.

9. Miller SA, Taveras EM, Rifas-Shiman SL, Gillman MW: Association between television viewing and poor diet quality in young children. Int J Pediatr Obes 2008, 3(3):168-176.

10. Ginioux C, Grousset J, Mestari S, Ruiz F: [Prevalence of obesity in children and adolescents attending school in Seine Saint-Denis]. Sante publique (Vandoeuvre-les-Nancy, France) 2006, 18(3):389-400.

11. Hainer V, Toplak H, Mitrakou A: Treatment modalities of obesity: what fits whom? Diabetes care 2008, 31(Suppl 2):S269-277.

12. Browne D: Exercise by prescription. Journal of the Royal Society of Health 1997, 117(1):52-55.

13. Brownell KD, Kaye FS: A school-based behavior modification, nutrition education, and physical activity program for obese children. The American journal of clinical nutrition 1982, 35(2):277-283.

14. Clinical guidelines on the identification, evaluation, and treatment of overweight and obesity in adults: executive summary. Expert Panel on the Identification, Evaluation, and Treatment of Overweight in Adults. Am J Clin Nutr 1998, 68(4):899-917.

15. CDC Pediatric Growth Charts. [http://www.cdc.gov/growthcharts].

16. Barlow SE, Dietz WH: Obesity evaluation and treatment: Expert Committee recommendations. The Maternal and Child Health Bureau, Health Resources and Services Administration and the Department of Health and Human Services. Pediatrics 1998, 102(3):E29.

17. Lama More RA, Alonso Franch A, Gil-Campos M, Leis Trabazo R, Martinez Suarez V, Morais Lopez A, Moreno Villares JM, Pedron Giner MC: [Childhood obesity. Recommendations of the Nutrition Committee of the Spanish Association of Pediatrics. Part I. Prevention. Early detection. Role of the pediatrician]. An Pediatr (Barc) 2006, 65(6):607-615.

18. Birch LL, Parker L, A B, (eds): Early Childhood Obesity Prevention Policies Committee on Obesity Prevention Policies for Young Children. 2011.

19. McNemar Q: Note on the sampling error of the difference between correlated proportions or percentages. Psychometrika 1947, 12(2):153-157.

20. Wilcoxon F: Individual comparisons of grouped data by ranking methods. J Econ Entomol 1946, 39:269.

21. Rozin P: The meaning of food in our lives: a cross-cultural perspective on eating and well-being. Journal of nutrition education and behavior 2005, 37(Suppl 2):S107-112.

22. Gubbels JS, Kremers SP, Stafleu A, Dagnelie PC, de Vries SI, de Vries NK, Thijs C: Clustering of dietary intake and sedentary behavior in 2-year-old children. The Journal of pediatrics 2009, 155(2):194-198.

23. van der Horst K, Timperio A, Crawford D, Roberts R, Brug J, Oenema A: The school food environment associations with adolescent soft drink and snack consumption. Am J Prev Med 2008, 35(3):217-223.

24. Lindsay AC, Sussner KM, Greaney ML, Peterson KE: Influence of Social Context on Eating, Physical Activity, and Sedentary Behaviors of Latina Mothers and Their Preschool-Age Children. Health Educ Behav 2009, 36(1):81-96

25. Lake JK, Power C, Cole TJ: Child to adult body mass index in the 1958 British birth cohort: associations with parental obesity. Archives of disease in childhood 1997, 77(5):376-381.

26. Danielzik S, Langnase K, Mast M, Spethmann C, Muller MJ: Impact of parental $\mathrm{BMI}$ on the manifestation of overweight 5-7 year old children. Eur J Nutr 2002, 41(3):132-138.

27. Sekine M, Yamagami T, Hamanishi S, Handa K, Saito T, Nanri S, Kawaminami K, Tokui N, Yoshida K, Kagamimori S: Parental obesity, lifestyle factors and obesity in preschool children: results of the Toyama Birth Cohort study. J Epidemiol 2002, 12(1):33-39.

28. Classen TJ: Measures of the intergenerational transmission of body mass index between mothers and their children in the United States, 19812004. Economics and human biology 2010, 8(1):30-43.

29. Laitinen J, Power C, Jarvelin MR: Family social class, maternal body mass index, childhood body mass index, and age at menarche as predictors of adult obesity. The American journal of clinical nutrition 2001, 74(3):287-294.

30. Casey PH, Simpson PM, Gossett JM, Bogle ML, Champagne CM, Connell C, Harsha D, McCabe-Sellers B, Robbins JM, Stuff JE, et al: The association of child and household food insecurity with childhood overweight status. Pediatrics 2006, 118(5):e1406-1413. 
31. Gundersen C, Lohman BJ, Garasky S, Stewart S, Eisenmann J: Food security, maternal stressors, and overweight among low-income US children: results from the National Health and Nutrition Examination Survey (1999-2002). Pediatrics 2008, 122(3):e529-540.

32. Kromeyer-Hauschild K, Zellner K, Jaeger U, Hoyer H: Prevalence of overweight and obesity among school children in Jena (Germany). Int $J$ Obes Relat Metab Disord 1999, 23(11):1143-1150.

doi:10.1186/1475-2891-10-132

Cite this article as: Gregori et al.: The "Snacking Child" and its social network: some insights from an italian survey. Nutrition Journal 2011 10:132.

Submit your next manuscript to BioMed Central and take full advantage of:

- Convenient online submission

- Thorough peer review

- No space constraints or color figure charges

- Immediate publication on acceptance

- Inclusion in PubMed, CAS, Scopus and Google Scholar

- Research which is freely available for redistribution 